\title{
URBAN LIGHT RAIL TRANSPORTATION SYSTEMS CATENARY LINE ANTI-ICING APPLICATIONS; LABORATORY AND FIELD TESTS
}

\author{
Ümit ER ${ }^{1}$, Fatih Hayati ÇAKIR ${ }^{2, *}$ \\ ${ }^{1}$ Mechanical Engineering Department, Engineering-Architecture Faculty, Eskişehir Osmangazi University, Eskişehir, Turkey \\ ${ }^{2}$ Eskişehir Vocational School Eskişehir Osmangazi University, Eskişehir, Turkey
}

\begin{abstract}
Problems such as freezing, icing, and/or snow accumulation in machine systems during winter can adversely affect the performance of such systems, sometimes even stopping them altogether. One system affected by winter conditions is energy transmission lines. Without intervention, snow and/or ice accumulating on electrical wires can cause electrical transmission performance to drop and, in extreme cases, can cause wire breakage due to heavy wires. One of the energy transmission system where power lines are open to the atmosphere is the pantograph-catenary system that takes up electrical energy. Frosting and ice accumulation on the catenary lines leads to arc formation and, in some cases, can interfere with electrical conduction between the pantograph and the catenary line. In the case of light rail transportation systems, this problem may lead to greater problems than in other rail systems. In Turkey, activities undertaken in preparation for winter and route maintenance in the intercity railway transmission lines are well known, but procedures for light rail systems are in their infancy. In particular, the use of light rail systems in cold regions, where conditions are more difficult, creates certain problems. Anticipation of problems that may arise is vital for transportaion it requires research studiues to solve such inevitable problems. In this study, an experimental setup is designed to simulate snow and dew formation on copper wires in an attempt to prevent/eliminate the icing problem that occurs on urban light rail transportation system catenary lines. Field tests have also been carried out by applying an anti-icing chemical solution on the catenary lines of the Eskişehir urban light rail transport system (ESTRAM). As a result of the field tests, it was observed that the application of mono-ethylene glycol to wires can reduce arc formation and wear of the lines considerably. It has even been found that the application of mono-ethylene glycol before freezing of the line has the potential to reduce wear, breakdown and maintenance costs in catenary lines.
\end{abstract}

Keywords: Anti-icing, Arc formation, Catenary-pantograph contact, Light rail transport, Tribology

\section{INTRODUCTION}

The use of electricity instead of fossil fuels in urban public transportation vehicles is becoming increasingly widespread due to the benefits it provides, especially in terms of the environment and human health. New generation batteries and storage technologies have not yet been introduced for use in the transmission of electrical energy in urban light rail vehicles with ever-improving performance. In these systems, the method commonly used in the transmission of energy to vehicles is the catenarypantograph system. A catenary line is a system that allows a flow of electric current from a transformer center to the rail lines via copper profiles along the route. The pantograph system, on the other hand, is an element that allows the momentary transmission of electricity from a catenary wire to the vehicle in motion. This transmission occurs when the pantograph system contacts the catenary line with a certain force. Pantograph and catenary systems can be designed in different shapes for different applications while maintaining the basic principle. The main problems encountered in the catenary-pantograph system are a misalignment of lines, wind resistance, vibration-induced problems, interruption of contact in the pantograph-catenary system, overheating, and arcing [1]. Studies have shown that arc formation from a variety of sources causes considerable damage to the catenary-pantograph system [2].

*Corresponding Author: fcakir@ogu.edu.tr

Receiving Date: 31 January 2018 Publishing Date: 29 June 2018 
Dew formation and catenary line icing can occur in winter conditions especially at night when there are no routes in operation. When necessary precautions are not taken, an ice layer formed on catenary wires interrupts the connection between the pantograph and the catenary, preventing the vehicle from receiving electricity and making the movement of the vehicle impossible. It is obvious that such a problem would cause serious damage and create problems for public transport traffic. With the transmission of electricity from the catenary line to the pantograph, the lines heat up a certain amount and the ice layer of the copper wire is broken by the pantographs carbon strip. In order for these conditions to occur, there should be auto de-icing of ice layers, the temperature and humidity of the air must not exceed certain values and intervals between journeys should not be too long. The problem does not always occur all along the line. It is a common occurrence that contact is partially interrupted in the case of partial icing of the catenary. During the night especially, when there is no movement on the lines, and with the effect of a decrease of air temperature, increases ice formation and there could be various difficulties during the first morning journeys. The catenary line and the pantograph contact point can be interrupted at many places. This leads to the formation of an arc between the carbon band in the pantograph and the catenary line. It has been reported that the temperature of the resulting arc can reach up to $3000{ }^{\circ} \mathrm{C}$ [3]. This situation can cause serious damage to the carbon strip of the pantograph, or to the catenary line. In order to reduce such damage, there are systems that can detect the situation and automatically stop the pantograph-line contact by retracting the pantograph if necessary [4], [5]. Various solutions have been developed and new possible solutions have been studied regarding the problem of icing on catenary lines, and these are frequently used in urban light rail transportation systems.

The pantograph system is a system that allows rail vehicles and trolley buses to receive electricity while they are on the move. In this system, an arm that is stretched by a certain tensile force $(80 / 90 \mathrm{~N}$ for light rail system tools) is in contact with the tension-carrying catenary wire and receives the energy required for movement. In particular, there is no external power unit in most inner rail system applications. For this reason, the movement of the vehicle depends only on the continuity of the contact between the pantograph and the catenary. Multi-arm pantograph systems are used to provide this basis. The pantograph system abrades some of the catenary wire during movement. The catenary lines must be positioned at a certain height tolerance so that this can be done regularly. Dropper wires are used to protect this height. This wire also carries a certain portion of the voltage in the line. The pantograph element is a plate made of a carbon graphite material, which is in contact with the copper profile forming the catenary line. This plate also acts as a solid lubricant to reduce wear during contact. The carbon strip provides high electrical conductivity, a low friction coefficient and high abrasion resistance to the pantograph system. The catenary lines are positioned diagonally in order to avoid the wearing of only a certain portion of the carbon strips. A high-voltage alternating current is used for power transmission in long distance electric train systems. This is because the alternating current is more economical than direct current, and practical and long-distance transmission is more suitable [6]. A high voltage also means thin wire sectioning. In urban transportation, light rail systems that use electricity from overhead wires require the use of direct currents with lower voltage values due to increased pedestrian and vehicle safety requirements. This necessity brings with it an increasing area of wire cross sectioning which increases the risk of snow accumulation and consequently icing in urban electricity transmission lines.

The main methods developed to combat icing problems in winter conditions are shown in Figure 1. This study focuses on the prevention of icing by considering the weather and working conditions of Eskişehir province (Turkey) and the ESTRAM Company. When the cost and ease of application of the methods are considered, the chemical solutions method of icing prevention comes to the forefront. One of the most common chemicals known for its anti-icing properties is mono-ethylene glycol [7]. In aviation in particular, it is a common application to spray mono-ethylene glycol containing different additives onto aircraft in order to prevent ice formation during flight. There have been a number of studies which report that glycol-based solutions can improve tribological properties in contact situations [8]. 


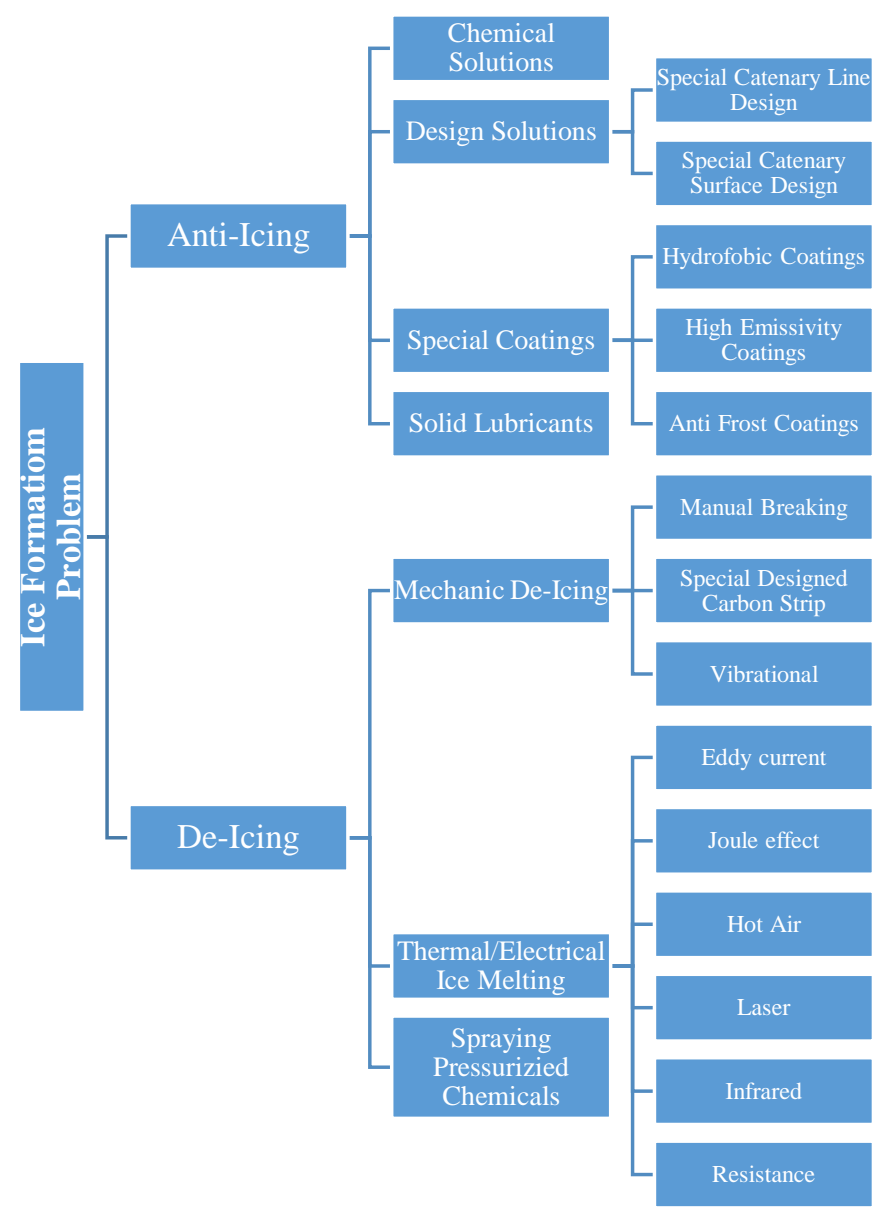

Figure 1. Proposed solutions for the icing problem in power lines [9]

Several anti-icing chemicals have been developed for different applications [10]. The choice of chemical that is appropriate for different a particular application is quite important. In this study, a procedure recommended in the literature has been used for this selection [11]. The selection criteria for the chemical chosen in this application are listed as follows: it should not be harmful to human or environmental health; it should not reduce or interfere with electricity transmission; it should not lead to extra friction resistance between pantograph and catenary; it should be used in an open atmosphere; it should not be affected by humidity; it should be easy to apply, staying viscose long enough to accommodate the point of application for some time; and the cost of the chemicals should be affordable. It should be noted that the applied chemicals may be removed from the surface by friction, so it would be necessary to repeat the application on a daily basis. In this context, the use of hydrophobic chemicals does not seem feasible. Considering all these reasons, glycol-based anti-icing chemicals are considered and mono-ethylene glycol is preferred for this application. The organic nature of the ethylene glycol species has played an important role in favoring the low incidence of corrosion. The use of monoethylene, di-ethylene and propylene glycol in aerospace applications and non-flammable petroleum products has been encouraging. Non-Newtonian liquids with similar properties are also susceptible to being investigated with viscous characters. There have been studies using polymer additives to increase the viscosity of the glycol based chemicals in the literature [12]. It should also be pointed out that it is possible to develop more suitable chemicals taking into consideration the factors mentioned above.

In the literature, anti-icing chemical usage has been investigated and there are many applications in the aviation and power transmission industries, but studies concerning railway systems are limited. In this study, laboratory and field experiments have been carried out to solve this problem by applying chemical 
solutions to prevent/retard ice formation. As a result of preliminary experiments and field tests, it can be seen that with the presence of mono-ethylene glycol, ice accumulation and arc formation can be decreased in many cases, especially before the first morning journeys. Using anti-icing chemicals has the potential to help the contact to run smoothly and reduce the possibility of contact failure as well as reducing maintenance costs in urban light rail transportation lines.

\section{MATERIALS AND METHOD}

There are many forms of ice and snow. There have been many studies that focus on predicting levels and types of ice formation. When sources related to ice formation in the literature are examined, it can be noted that twenty different models have been developed to predict ice formation [13]. These models are developed in different climate conditions, but some also apply to local cases. The widely-accepted Imai model has been developed with the aim of predicting the amount of ice build-up in power lines [14]. According to this model, the formation and accumulation of ice in wires increases in direct proportion to a decrease in the air temperature and/or an increase in wind speed. In Equation (1), an equation expressing ice formation is given [13]. In this equation, $\mathrm{V}$ expresses wind speed, $\mathrm{T}$ is air temperature, $t$ is unit time, and $\mathrm{M}$ is ice mass formed. $\mathrm{C}_{1}$ is the icing constant:

$$
\frac{d M}{d t}=C_{1} \sqrt{V R}(-T)
$$

When the ice formation and accumulation models are examined in this contextt can be said that in Turkey there is a risk of accumulation of ice load during winter in cities where terrestrial climate is seen especially when there are long distances between consecutive voyages, which may lead to probems.

\subsection{Laboratory Experiments}

There are many special systems which have been developed to monitor the formation and accumulation of ice and snow [13], [15], [16]. Most of these systems are capable of controlling air temperature, humidity and wind speed. The prototype system developed within the scope of this study has aimed to simulate the formation of both dew and snow, but laboratory studies have only managed to observe snow formation. This was seen as accaptable since the results are good indicator of field tests, considiring simulation of advanced icing conditions requires more sophisticated systems. In this system, a compressor and a shutdown valve are used under room conditions of $23{ }^{\circ} \mathrm{C}$ and $60 \%$ humidity to ensure snow, with compressor coolant (R600a) drop valve outlet pressure at -0.2 bar and expansion outlet return pressure 15 bar. As soon as the system started operating, snow formation was observed.

With this device, an outer surface temperature of copper piping is obtained as low as $-13.5^{\circ} \mathrm{C}$. During the cycle, the cooling fluid pressure is increased by expanding the pipe diameter and compressed again to obtain a closed loop system. The elements used in this embodiment are produced by means of systems that are used in a conventional refrigerator. The prototype is shown in Figure 2, and prototype information is given in Table 1 .

Table 1. Prototype snow accumulation device properties

\begin{tabular}{cc} 
Parameters & Magnitudes \\
\hline Coolant Type & R600a \\
Inlet Pressure & $-0.2 \mathrm{Bar}$ \\
Outlet Pressure & $15 \mathrm{Bar}$ \\
Room Temperature & $23^{\circ} \mathrm{C}$ \\
Humidity & $60 \%$ \\
Minimum Temperature & $-13.5^{\circ} \mathrm{C}$ \\
Type of Icing & snow accumulation \\
\hline
\end{tabular}




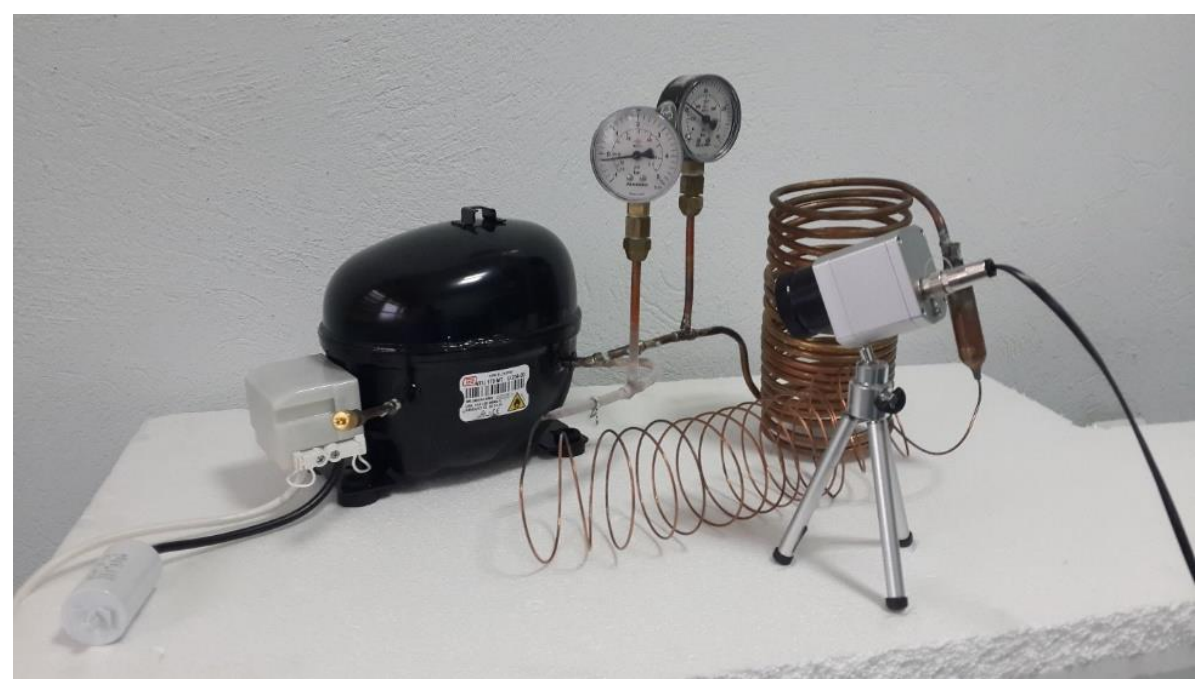

Figure 2. Prototype snow accumulation device and test setup

As the copper pipes used in the developed device continuously provide a sudden temperature drop in stationary air, the system enables snow formation in a short time. The prototype generates different temperatures at different sections. The temperature distribution in the observed section was obtained with the help of a thermal camera. It can be seen that a certain section can provide a homogenous temperature gradient. This section was divided by a band. In order to prevent effects which may occur during the experiment, the chemical applied portion and the reference portion were separated from each other by a band in each experiment. A cable splice was tightly wrapped around the pipe so that it was visible on the thermal camera. The image taken during the experiment with the thermal camera is shown in Figure 3. As can be seen in the figure, a temperature of around $-13{ }^{\circ} \mathrm{C}$ was obtained in the section shown as dark blue. This temperature shows a slight decrease at the beginning and end of the observed channel. A slightly lighter blue area shows a temperature of around $-10^{\circ} \mathrm{C}$.

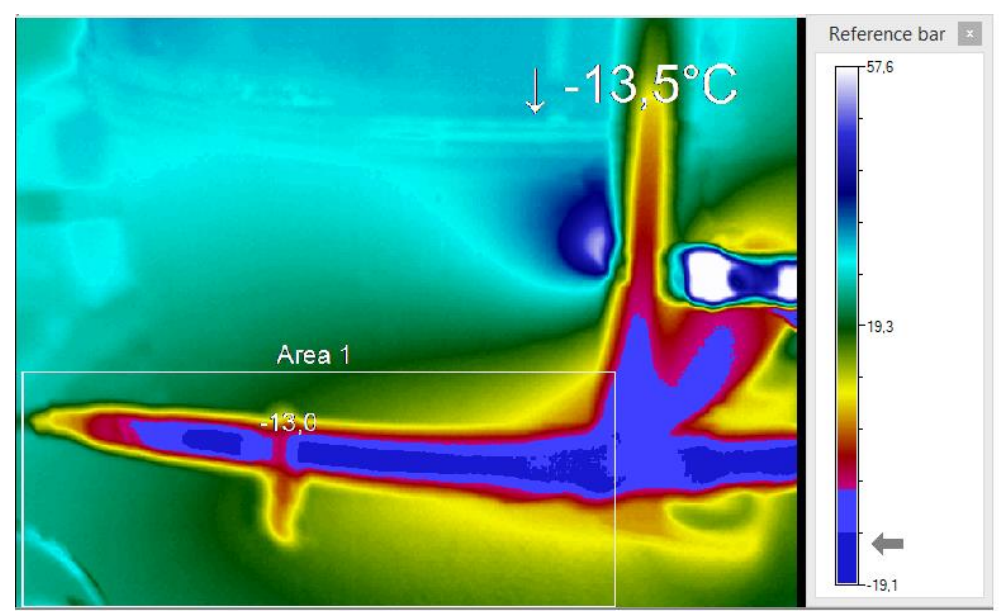

Figure 3. Thermal camera image of the test area

As a result of preliminary experiments, it was decided that ten minutes of experiment duration would be enough to obtain a meaningful amount of snow. After the experimental set-up was arranged, experiments were carried out for ten minutes under three different conditions. It has been determined that the chemicals applied to the surface in the experiments performed do not significantly affect the temperature distribution of the system. In the reference experiment, the system was run for ten minutes without any 
application, and snow was observed. It can be seen that the amount of snow increases with the length of the test period. In the samples where mono-ethylene glycol is applied, it seems that the applied chemical significantly reduces the accumulation of snow, especially in sections up to $-10{ }^{\circ} \mathrm{C}$. As can be seen in Figure 3, the temperature in the middle section is close to $-13{ }^{\circ} \mathrm{C}$, and the amount of snow seems to decrease considerably, compared to the reference test. It should also be noted that this temperature (-13 ${ }^{\circ} \mathrm{C}$ ) is close to the freezing point of the mono-ethylene glycol, so below this point the mono-ethylene glycol itself starts to freeze. This effect appears to be more evident, especially in a mixture of monoethylene and water. Figure 4 shows the amount of snow observed over increasing periods. In reference group (a), no chemicals were applied and snow formation was observed. In the groups (b) and (c), monoethylene glycol was applied to the left side of the piping and no treatment was performed on the right side. Mono-ethylene glycol was applied in different ratios in groups (b) and (c). The observed area was cleaned with alcohol prior to each test. After cleaning, any snow formation was observed, and it was also confirmed that the observed process did not affect the snow performance. After this, the next experiment was started.

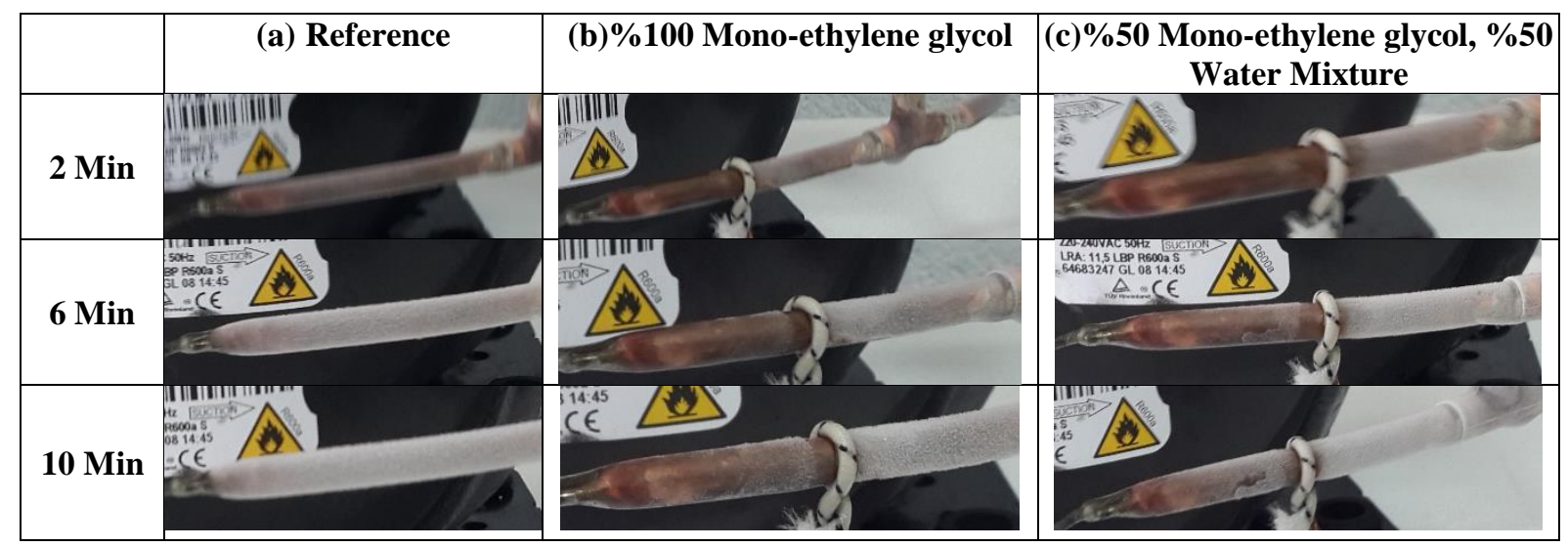

Figure 4. The observed snow accumulation conditions at increasing times under different conditions

Mono-ethylene glycol was supplied in commercial purity. The chemical properties of the supplied mono-ethylene glycol are given in Table 2.

Table 2. Mono-ethylene glycol chemical properties [17]

\begin{tabular}{cc} 
Properties & Magnitudes \\
\hline Chemical Formula & $\mathrm{C}_{2} \mathrm{H}_{6} \mathrm{O}_{2}$ \\
Molecular Weight, g / mol & 62.07 \\
Appearance & Colorless Liquid \\
Specific Density, g / cm & 1.115 \\
Freezing Point, ${ }^{\circ} \mathrm{C}$ & -13 \\
Boiling Point, ${ }^{\circ} \mathrm{C}$ & $196-198$ \\
Viscosity, $25^{\circ} \mathrm{C} . \mathrm{cp}$ & 16.9 \\
Flash Point (closed container), ${ }^{\circ} \mathrm{C}$ & 110 \\
Amount of water, max ppm & 750 \\
\hline
\end{tabular}

The catenary line elements, which were applied $100 \%$ with mono-ethylene glycol, show a positive performance in the snow experiment, were kept in a refrigerator without a frost prevention system for a long period with ice formation and accumulation being observed. It was seen that application of monoethylene glycol to the catenary parts was also effective against ice formation and accumulation in this case. Figure 5, shows the images of long-term tests performed by ESTRAM. 

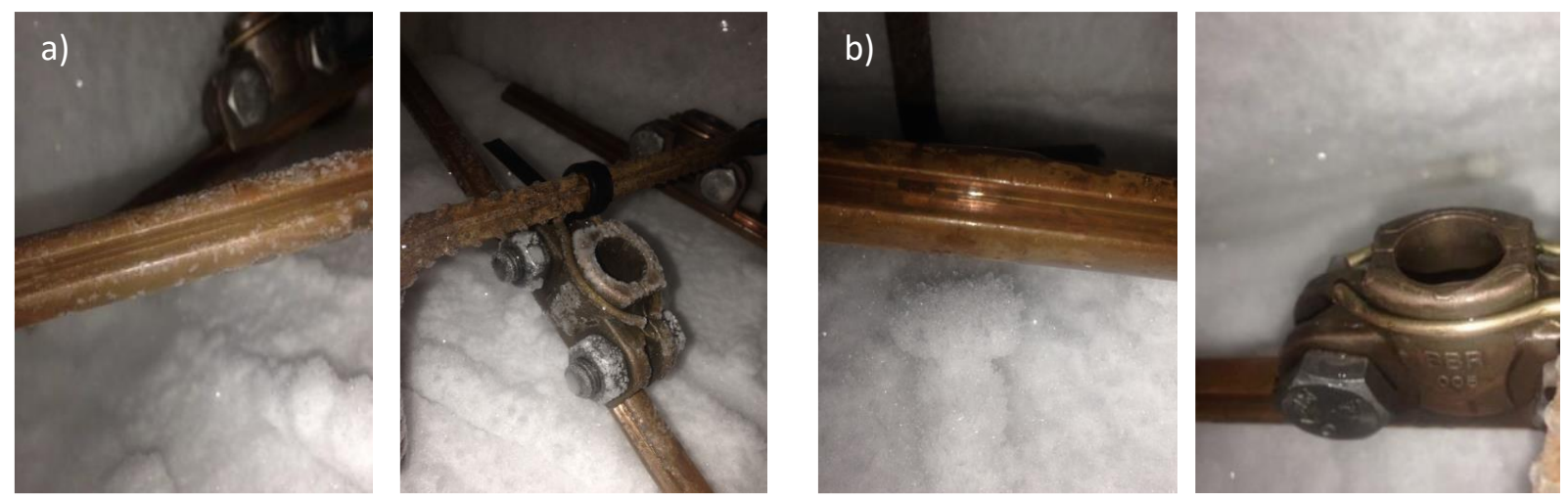

Figure 5. Long-term icing test a)Reference b) 100\% Mono-ethylene glycol [18]

In addition to these tests, a section of the catenary wire was isolated in order to observe whether monoethylene glycol could damage the catenary wires prior to field tests. The chemical and catenary wire were placed in a closed chamber for one week while tests were conducted. As a result of these, it is reported that no visible corrosive effect was observed on the wiring and that there was no negative effect on the electrical conductivity of the copper wires, so field experiments were allowed. It should be noted that in order to understand the long-term effects of the proposed application, further studies and corrosion tests are required.

\subsection{Field Tests}

As a result of the positive results obtained from the laboratory experiments, it was decided to carry out a field trial. Tram routes that are used at an entrance to the tram parking garage were chosen. After completing their daily runs, test trams were parked at the garage with line power deactivated and the road to be used grounded on 04.01.2018 with the permission of ESTRAM. Two routes (6 and 7) were tested for this procedure, one of which was the reference route. The seventh route was accepted as a reference sample and no operations were performed on this line. On the sixth route, $100 \%$ monoethylene glycol was applied by brush, taking all work safety precautions. Mono-ethylene glycol was applied at 21:00 for the purpose of preventing ice accumulation. The electricity supply was cut off before application. The application was carried out by impregnating a brush with chemicals and applying this to the wires with gentle pressure. The application is shown in Figure 6.
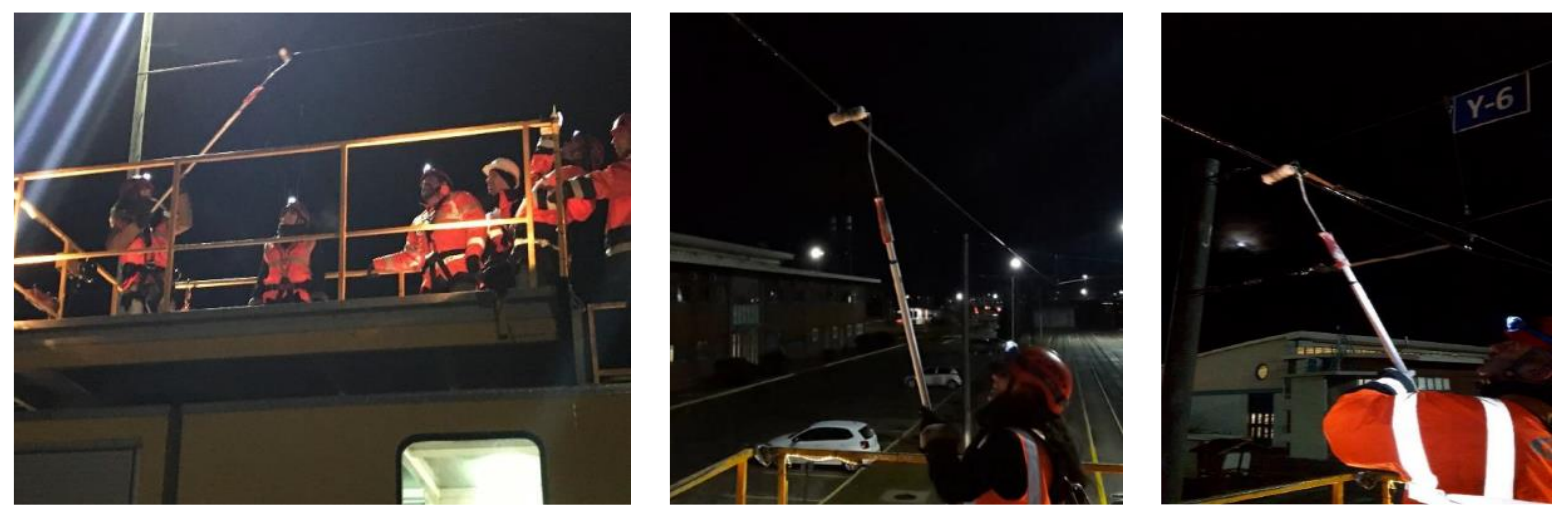

Figure 6. Application of mono-ethylene glycol to catenary lines [18]

The weather conditions for the field test are given in Table 3. Monitoring of the catenary lines was performed at 05:00, approximately eight hours after the application. No icing was reported at 21:00 prior 
to the mono-ethylene glycol application. Ice accumulation was observed at the reference lines through the effects of temperature differences and air humidity. The observation was made through the motion of trams in the observed lines [18].

Table 3. Field test parameters [19]

\begin{tabular}{cc} 
Parameters & Magnitudes \\
\hline Ambient Average Temperature & $3{ }^{\circ} \mathrm{C}$ \\
Average Humidity & $91 \%$ \\
Dew Temperature Point & $2{ }^{\circ} \mathrm{C}$ \\
Minimum Temperature & $-2{ }^{\circ} \mathrm{C}$ \\
Type of Icing & Dew \\
Wind Speed & $5 \mathrm{Km} / \mathrm{h}$ \\
\hline
\end{tabular}

\section{RESULTS AND DISCUSSION}

According to laboratory test results, an application of mono-ethylene glycol is expected to be effective in the prevention of ice formation when ambient temperature does not fall below $-10{ }^{\circ} \mathrm{C}$. In the longterm icing test, mono-ethylene glycol displayed effective performance in reducing ice build-up in catenary wire elements. According to the field test results, it was observed that arc formation in lines coated with mono-ethylene glycol under the conditions specified in Table 3 decreased considerably. The reduction in arc formation is shown in Figure 7. One line was observed as a reference line. On this line, during night-time when there were no runs, dew accumulated on the catenary lines. As a result, electrical conduction was interrupted and arc formation was observed. Arc formation in winter conditions in Eskisehir severely reduces the life of the catenary line and the pantograph carbon strip. On the line where mono-ethylene glycol was applied, visible arc formation was not realized. However, according to the electrical measurements of the system, it was reported that there was a slight backlash which would not damage the system without electricity interruption. It is believed that incomplete or improper application of the chemical to the catenary lines caused the partial arc formation. In the field trial, it was understood that improvement observed under laboratory conditions could be applied in the field. It is believed that the applied chemical would be effective in weather conditions down to $-10^{\circ} \mathrm{C}$, and could significantly reduce ice build-up and arc formation in many cases. According to these results, it has been determined that there is a potential for mono-ethylene glycol application to prevent/retard ice accumulation prevention in catenary lines.
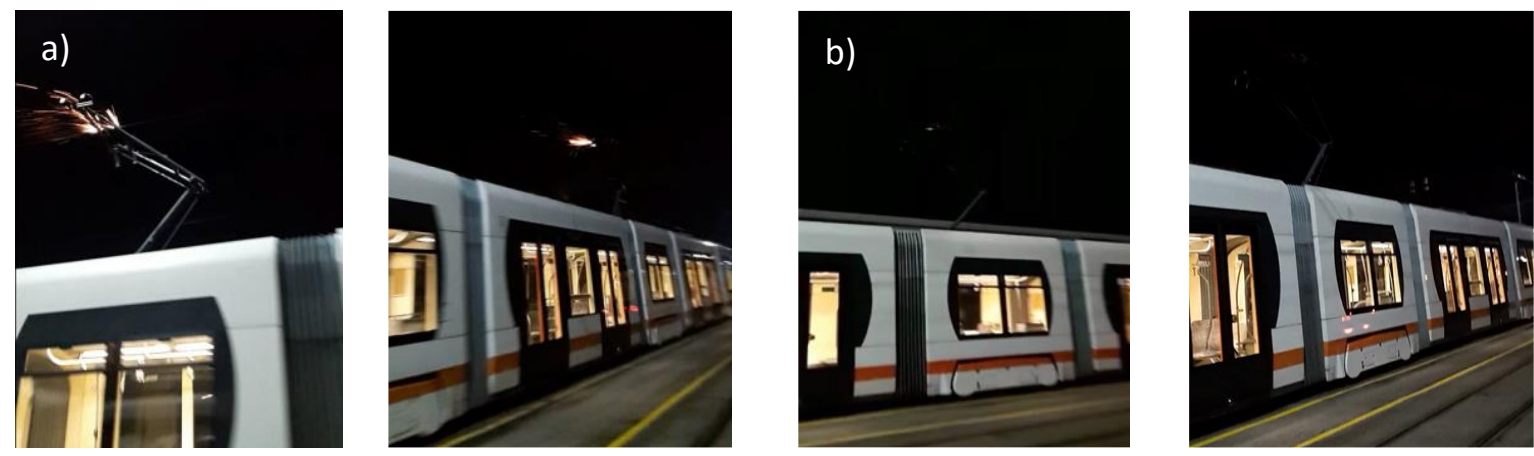

Figure 7. Observed arc formation in field tests a) Reference b) \%100 Mono-ethylene Glycol

\section{CONCLUSION}

In this study, the problem of freezing and icing in heavy winter conditions on catenary lines in urban light rail transportation systems was discussed and known solution techniques were investigated. By evaluating the conditions and formation of icing, possible solution proposals were analyzed. 
Considering the cases where the frost phenomenon is not frequent, but causes problems for several weeks of the year, the performance of anti-icing chemicals were examined. It has been shown that frost formation can be prevented or delayed by the application of mono-ethylene glycol to catenary lines. It was noted that there is a potential to prevent arc formation and to prevent electrical conduction interruption in catenary lines. It can also be said that the applied chemical improves the tribological properties of the system if we consider the lubricating effects of reducing friction and abrasion in waterbased environments. It is envisaged that the performance of the application can be further improved by designing a machine which allows for brushing of the chemical coating to be performed evenly. In addition, taking into account cost and time duration, alternative chemicals should be explored with a view to providing better results. The improvement observed in laboratory tests was also observed in field tests. It is believed that the applied chemical will significantly reduce the formation of icing up to $-10^{\circ} \mathrm{C}$, as well as preventing it in many cases. It is also thought that the effects of the applied chemicals should be examined separately before any long-term use of the chemicals or the addition of anticorrosive compounds is considered.

\section{ACKNOWLEDGEMENTS}

The authors would like to thank Öznur Erdoğan and Nilüfer Kanmaz, who took part in the field tests within the scope of this study, and the ESTRAM Maintenance Division for their support.

\section{REFERENCES}

[1] Yaman O, Karaköse M, Aydın İ ve Akın E. (2014). Görüntü işleme ve bulanık mantık tabanlı pantograf geometrik modelin tespiti. Yaman, O. (Haz.). 22. Sinyal işleme ve İletişim Uygulamaları Kurultay1 (SIU 2014). ss.686-689. Trabzon, Türkiye: IEEE.

[2] Aydin I, Karakose M and Akin E. Anomaly detection using a modified kernel-based tracking in the pantograph-catenary system. Expert Syst. Appl., vol. 42, no. 2, pp. 938-948, Feb. 2015.

[3] Szafránski, Z. Winter and Railways, International Union of Railways Rail System Department for the RSF, 2011.

[4] Bhargava B. Railway electrification systems and configurations, 1999 IEEE Power Engineering Society Summer Meeting. Conference Proceedings (Cat. No.99CH36364), Edmonton, Alta., 1999, pp. 445-450 vol.1.doi: 10.1109/PESS.1999.784389

[5] Landi A, Menconi L and Sani L. "Hough transform and thermo-vision for monitoring pantographcatenary system," Proc. Inst. Mech. Eng. Part F J. Rail Rapid Transit, vol. 220, no. 4, pp. 435-447, Jan. 2006.

[6] Baxter A. Network Rail A Guide to Overhead Electrification, London, 132787-ALB-GUN-EOH000001, 2015.

[7] Coffey DA. Ashrawi SS. and Nieh EC. Aircraft wing de-icers with improved holdover times, US 5386968 A.

[8] Tomala A, Karpinska A, Werner, WSM, Olver A and Störi H. Tribological properties of additives for water-based lubricants. Wear, vol. 269, no. 11-12, pp. 804-810, Oct. 2010.

[9] Er Ü and Çakir FH. Kent İçi Hafif Rayli Ulaşim Sistemleri Katener Hatlarinda Buzlanma Problemi Ve Bakim Yöntemlerinin İncelenmesi, presented at the VIII. Bakım Teknolojileri Kongresi ve Sergisi, Denizli, 2017, pp. 195-201. 
[10] Muthumani A, Fay L, Akin M, Wang S, Gong J and Shi X. Correlating lab and field tests for evaluation of deicing and anti-icing chemicals: A review of potential approaches. Cold Reg. Sci. Technol., vol. 97, pp. 21-32, Jan. 2014.

[11] Nixon WA and Williams AD. "A guide for selecting anti-icing chemicals, version 1.0," IIHR Tech. Rep, vol. 420, 2001.

[12] Carder CH, Garska DC, Jenkins RD and McGuiness MJ. Aircraft deicing/anti-icing fluids thickened by associative polymers. US5708068A, 13-Jan-1998.

[13] Heyun L, Xiaosong G and Wenbi T. Icing and Anti-Icing of Railway Contact Wires, in Reliability and Safety in Railway, X. Perpinya, Ed. InTech, 2012.

[14] Makkonen L. Modeling of ice accretion on wires, J. Clim. Appl. Meteorol, 1984; vol. 23, no. 6, pp. 929-939

[15] Wang F, Li C, Lv Y, Lv F and Y. Du, Ice accretion on superhydrophobic aluminum surfaces under low-temperature conditions, Cold Reg. Sci. Technol., Jun. 2010, vol. 62, no. 1, pp. 29-33,

[16] Makkonen L, Laakso T, Marjaniemi M, and Finstad KJ Modelling and Prevention of Ice Accretion on Wind Turbines, Wind Eng., Jan. 2001, vol. 25, no. 1, pp. 3-21,

[17] DOTP, MEG, ANTFRIZ, GEC KİMYA SANAYİ̇. [Online]. Available: http://www.gec.com.tr/meg.htm. [Accessed: 19-Jan-2018].

[18] Erdoğan Ö and Kanmaz N. Katener-Pantograf Sistemlerinde Buzlanma Problemine Karşı Mono Etilen Glikol Uygulamas1, Eskişehir Osmangazi Üniversitesi, 2018.

[19] "Weather History for Anadolu University Airpor, TR | Weather Underground." [Online]. Available:https://www.wunderground.com/history/airport/LTBY/2018/1/4/DailyHistory.html?req _city $=\&$ req_state $=\&$ req_statename $=\&$ reqdb.zip $=\&$ reqdb. magic $=\&$ reqdb. wmo $=$. [Accessed: 25Jan-2018]. 